\title{
An Economic Model for Offshore Transmission Asset Planning Under Severe Uncertainty
}

\author{
Henna Bains ${ }^{\mathrm{a}, *}$, Ander Madariaga ${ }^{\mathrm{b}}$, Matthias C. M. Troffaes ${ }^{\mathrm{c}}$, Behzad Kazemtabrizi ${ }^{\mathrm{a}}$ \\ ${ }^{a}$ Department of Engineering, Durham University, Durham, DH1 3LE \\ ${ }^{b}$ Offshore Renewable Energy Catapult, Inovo Building, 121 George Street, Glasgow, G1 1RD, UK \\ ${ }^{c}$ Department of Mathematical Sciences, Durham University, Durham, DH1 3LE , UK
}

\begin{abstract}
The inherent uncertainties associated with offshore wind are substantial, as are the investments. Therefore, investors are keen to identify and evaluate the risks. This paper presents a model to economically evaluate projects from an offshore transmission owner's perspective by considering the revenue streams, capital costs, and operational expenditure. To allow a more realistic economic evaluation, data, regulatory information, and expert knowledge are collected, curated and, where necessary, combined with statistical techniques. A generic 1.2 GW project is used as a case study. This research contributes to a deeper understanding of the severe uncertainties involved in offshore transmission planning and their impact on a project's expected profit. Understanding their impact, through a sensitivity analysis where individually one factor is varied within an interval, supports informed decision making with limited information. Uncertainty in interest rates, planned operational expenditure and, particularly, cable failure rates were found to be critical to an investor's return. For the case study considered, comparing cable failure rates based on operational experience to inputs based on literature, resulted in a $64.2 \%$ lower net present value. In conclusion, further research into cable failures, and addressing the uncertainty in inputs used for economic evaluations could be beneficial to the industry.
\end{abstract}

Keywords: Offshore transmission, Interconnectors, Wind Energy, Uncertainty, Net present value

\section{Introduction}

The current energy policy of the UK focuses strongly on energy security, decarbonisation, and affordability. Accordingly, the fifth carbon budget recommends a reduction in carbon intensity to less than $100 \mathrm{gCO}_{2} / \mathrm{kWh}$ by 2030 [1]. This target, combined with other environmental policies, has opened a gap for renewables.

\footnotetext{
*I am corresponding author

Email addresses: henna.bains@durham.ac.uk (Henna Bains), ander.madariaga@ore.catapult.org. uk (Ander Madariaga), matthias.troffaes@durham.ac.uk (Matthias C. M. Troffaes), behzad.kazemtabrizi@durham.ac.uk (Behzad Kazemtabrizi)
} 
Offshore wind is one viable solution, and over the past decade, the amount of installed offshore wind globally has grown from 1.6 GW in 2008 to $23.1 \mathrm{GW}$ in 2018 [2]. 2016/17 saw a dramatic decrease in offshore wind prices as did 2019. UK projects that reached financial investment decision status in 2019 achieved a significantly lower than expected strike price of $£ 39.65 / \mathrm{MWh}$. This decrease results from maturing of the industry, technology and management practices, growing investor confidence and the introduction of 8-10 MW turbines. As the industry looks to become even more competitive in the future, investors are interested in assessing the risks given the inherent uncertainties.

The ownership structure of an offshore wind power plant varies between countries as detailed in [3, 4, 5]. The different ownership structures can be classified as third-party ownership, onshore transmission system operator ownership and developer ownership. The advantages and disadvantages to each approach are discussed in the literature in particular with regards to project finance, project design, and operating the assets. [5] suggests that the approach implemented in the UK is flexible, which has allowed the UK to deliver timely offshore projects that are designed to economically and efficiently connect offshore generation assets to the onshore grid, and therefore incentivising private investment in these assets [6]. In this work, we focus on the UK perspective who implements a third-party ownership structure called the offshore transmission owner (OFTO) regime [7]. This regime involves a separate entity (an OFTO) owning, financing, operating and maintaining the offshore transmission system.

To allow the electricity to be used onshore, each wind farm installed offshore is connected to the onshore grid by an offshore transmission system. An offshore transmission system usually includes the offshore substations, offshore cables, onshore cables and onshore substation. As offshore wind projects increase in capacity and move further offshore, the costs associated with the offshore transmission system also increase. Therefore, an economic evaluation over the project's lifetime is essential to investors.

During the last decade, several studies have conducted economic assessments of offshore wind projects. For example, [8] evaluates the merit of investing in high voltage direct current (HVDC) topologies over a range of project capacities by considering the costs associated with the investment, operations and maintenance, losses and energy not supplied. [9] investigates optimal offshore transmission system (OTS) configurations by taking into account the failure rate, repair rate, wind behaviour, selling price of energy, interest rates, acquisition costs, and installation costs. [10] compares investment and operating costs of high voltage alternating current (HVAC) and HVDC OTSs. In [11] the analysis considers the revenue stream for the entire offshore wind power plant and consequently, explores the effect of wind characteristics and other uncertain factors on income, through uncertainty analysis.

In the literature, two metrics, namely levelised cost of energy (LCoE) ([12, 13]) and net present value (NPV) $([9,11,14])$, are commonly used in economic evaluations and decision making. Many economic assessments evaluate the cost of an energy generation technology rather than from a particular investor's perspective. Therefore, little research has been done from an offshore transmission owner's perspective. These metrics depend on the revenue stream, capital expenditure and operational expenditure of a project. There has been considerable research into the capital expenditure (CAPEX) and operational expen- 
diture (OPEX) of offshore wind projects. In the literature CAPEX is estimated using the following methods: as a function of distance to shore or project capacity [13, 15], by values published in reports [12], or by summing individual component costs [9, 10]. Similarly, in the literature, OPEX is calculated by a variety of methods. [11] estimates turbine maintenance as a price per MWh, whereas [8] and [16] estimates maintenance as a percentage of the CAPEX. [9] considers money lost due to energy not supplied and [10] splits operating costs into maintenance and losses.

Unfortunately, economic evaluations of offshore wind projects are subject to many inherent uncertainties. Uncertainties could be due to a lack of relevant information, the level of robustness of the data, the way the data is presented or the need to predict future scenarios. Several studies have investigated the uncertainties associated with the entire offshore wind power plant and their impact of economic metrics [17, 18, 11, 19]. In particular, the impact of variations in the power generated by the wind farm is assessed. The work in [9] focuses on the offshore transmission system, but still considers the economic impact for the entire offshore wind power plant. Therefore, very little attention has been paid to assessing the impact of severe uncertainties from an offshore transmission owner's perspective. Furthermore, there exists uncertainty around the failure rates of export cables (a significant asset in the offshore transmission system) [20]. Large uncertainties in the input data do not necessarily imply a high economic impact on project performance. Therefore, as well as developing an economic framework for OTSs, this paper identities the uncertain model variables and assesses their impact on project performance. This assessment is valuable for investors who seek high profit and low-risk investments.

In this paper, we conduct analysis from the offshore transmission owners (OFTOs) perspective as they, among other investors, are involved in decision making, under severe uncertainty. There is merit in taking an investor's perspective as they play a vital role in the offshore wind industry. This different perspective requires current, publicly available, economic models to be reshaped to include elements such as revenue streams and loan repayments. In our economic assessment, we consider the repayment structure of the final transfer value (FTV) over time rather than CAPEX as an initial investment. The problem of non-linearity in the contractual income is overcome by careful evaluation of availability and a justified simplification to the contractual income. The analysis distinguishes random variables from those that are not, and applies statistical techniques accordingly. As suggested by the literature, the inclusion of the aforementioned economic elements allows a more realistic view as to how investors view future projects. Due to the nature of the OTS, the economic model contains severe uncertainty. In this paper, we discuss these uncertainties and assess the impact of them on the project's expected profit.

The rest of the paper is structured as follows. Section 2 defines how the NPV of the OTS is going to be calculated from an offshore transmission perspective. Section 3 formulates the revenue streams and discusses yearly system availability. Section 4 formulates the loan repayments and explores CAPEX by proposing and validating a 'bottom-up' evaluation approach. Section 5 presents methodology for operational expenditure (OPEX) evaluation. Details of a case study upon which we shall conduct our analysis, input data and results of the expected NPV evaluation are presented in Section 6. The impact of uncertain variables 
on expected NPV is assessed through interval analysis in Section 6. Finally, Section 7 outlines the conclusions of this work.

\section{Methodology Outline}

In order to assess the impact of severe uncertainties on an offshore transmission owner's expected profit, a framework to assess their profit is required. Consequently, an extensive literature review, including academic papers, industrial reports and economic evaluations of the entire offshore wind farm, has been conducted to build an economic model for a general OTS. Many studies assess the economic impact of project specifications such as capacity and distance from shore. This is not the focus of the work here. A fixed design, under consideration by projects currently in the planning and construction stage, is taken and used to assess the impact of uncertainty on the expected profit.

Computational aspects, including simulations and figures, have been performed in $\mathrm{R}$ [21] and PYTHON, using NUMPY [22] and MATPLOTLIB [23].

\subsection{Economic evaluation from different stakeholder's perspectives}

The ownership structure of an offshore wind power plant varies between countries. When conducting an economic evaluation, a specific stakeholder's perspective should be taken. Here, we take the UK market and conduct the analysis from the perspective of an offshore transmission owner (OFTO). This economic model could be adapted to other markets by changing aspects of the model that are no longer relevant, for example, changing the revenue stream to be in-line with a particular market's practice. Many parts of the model are likely to remain unchanged, such as CAPEX and OPEX.

The UK has an OFTO regulatory regime, which is different from other markets, and directly impacts how the business case is articulated. A developer builds the entire power plant but must hand the transmission assets to an OFTO when they are operational [24, 25]. The UK's energy regulatory body, Ofgem, regulate the transfer of assets and run a competitive tender process to select and award an OFTO licence to a company. The competitive tender process involves a cost assessment to determine the final transfer value (FTV) of the assets. The FTV is the amount the OFTO must pay the developer for the OTS. An OFTO is responsible for operating the OTS under long term licences that guarantee a revenue stream subject to satisfying performance requirements [26].

\subsection{Net Present Value}

NPV, chosen as it allows the inclusion of revenue streams, takes a discounted cash flow approach to evaluate the time value of money [27]. The discount factor, $d$, discounts future yearly cash flows to the present-day value [28]. NPV is the sum of these discounted future cash flows:

$$
\mathrm{NPV}=\sum_{t=0}^{T-1} \frac{V(t)}{(1+d)^{t}}
$$

Here, $t$ represents the year of operation, $V(t)$ the uncertain cash flow in that year and $T$ the project lifetime. This paper aims to use Eq. (1) to calculate a project's expected NPV. 
NPV only indicates if a project is expected to be profitable over its lifetime and not in each year. Individual negative $V(t)$ could significantly impact some companies involved. The main contributions to cash flow are contractual income, loan repayment for capital costs and operational expenditure:

$$
V(t)=\text { Contractual Income }_{t}-\text { Loan Repayment }_{t}-\text { Operational Expenditure }_{t}
$$

Details on how to evaluate contractual income, loan repayment and operational expenditure are given in Section 3, Section 4 and Section 5 respectively. Throughout this paper, this economic model is referred to as the NPV model.

The described NPV model can be summarised by Fig. 1, which gives a graphical representation of the NPV model showing the dependencies between model variables. The model variables with a double circle represent input parameters that are used to evaluate other model variables and ultimately evaluate the NPV of a project. Fig. 1 shows that contractual income, loan repayments, operational expenditure (planned and unplanned), and discount

rate are required to evaluate the NPV. This corresponds to Eq. (1) and Eq. (2). This NPV evaluation is for a specific topology which is represented in Fig. 11 as the input parameter termed technology. Fig. 1 is a visual summary of the equations that follow in the rest of the paper.

\section{Contractual Income}

In the UK, the national electricity transmission system operator pays the OFTO a base revenue (BR) to operate and maintain the OTS [29]. The BR is fixed for the first twenty-five years of the project. After twenty-five years, this is reviewed based on asset demand.

Under the regulatory regime, OFTOs are incentivised to maintain high levels of asset availability throughout the twenty-five year revenue period to limit financial losses to generators from network outages. Dependent on the yearly availability of the OTS, the OFTO receives a reward or penalty based around a target of $98 \%$ availability. This is described by Eq. (3) which has been produced in line with [29]. Under the regulatory regime, only $10 \%$ of the OFTO's base revenue is at risk due to availability, hence should the availability fall below $94 \%$ the OFTO would only obtain $90 \%$ of the base revenue. For availability greater than $94 \%$ the revenue increases linearly from $90 \%$ of the base revenue at $94 \%$ availability to $105 \%$ of the base revenue at $100 \%$ availability. It is to be noted that this model fits with the $98 \%$ availability target since it can be seen that at $98 \%$ availability, the OFTO receives $100 \%$ of the base revenue.

$$
\begin{array}{cl}
\text { Contractual } \\
\text { Income }
\end{array}= \begin{cases}0.9 \mathrm{BR}, & \text { if } Y_{t}<0.94 \\
\left(0.9+\left(Y_{t}-0.94\right) 2.5\right) \mathrm{BR}, & \text { if } Y_{t} \geq 0.94\end{cases}
$$

Here, $Y_{t}$ represents the average availability of the OTS in year $t$ and BR is the base revenue, discussed below.

Wind characteristics are not considered in the revenue stream as they are not directly considered under the OFTO regulatory regime as a fixed BR is assigned. Uncertain weather 


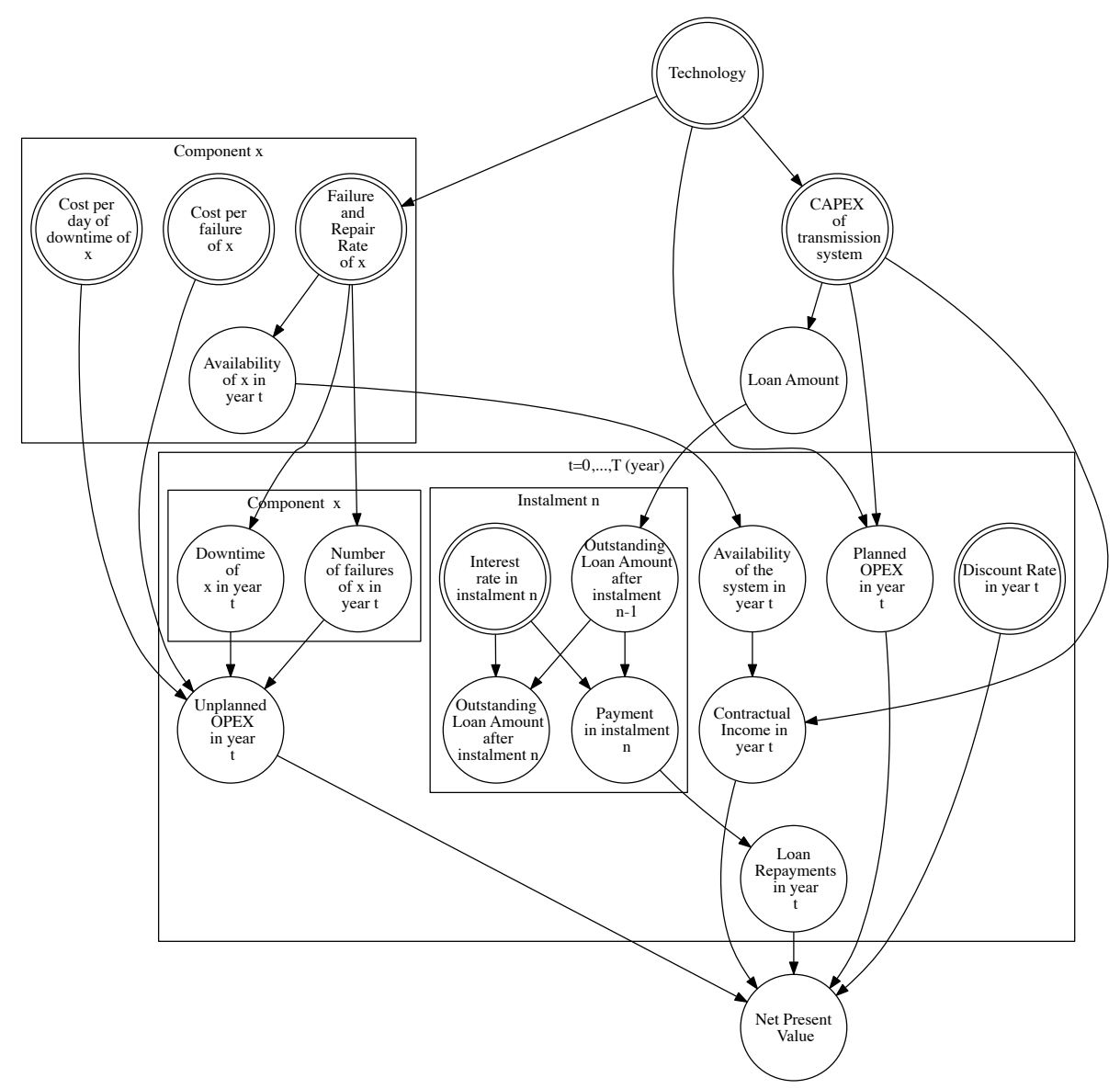

Figure 1: Graphical representation of the net present value (NPV) model for a UK offshore transmission system (OTS).

conditions do play a role regarding OPEX and are studied in the sensitivity analysis against repair time in Section 6.4

\subsection{Base Revenue}

The base revenue is determined in the OFTO licence and reflects the costs of performing the OFTO's obligations and costs of financing the investment. A project's BR is required in the NPV model but unknown in advance of a project licence. Analysis of Ofgem cost assessments [30, for fully commissioned UK offshore wind projects, identified a relationship between CAPEX and BR. Using linear regression and the method of least squares, we obtained a linear model of the form presented in Eq. (4) with an $R^{2}$ value of 0.9783 . $R^{2}$ is a goodness-of-fit measure [31]. An $R^{2}$ value of one represents models that explain all of the variation in the response variable around its mean, whereas an $R^{2}$ value of zero indicates that the model does not explain all of the variation in the response variable around its mean. 


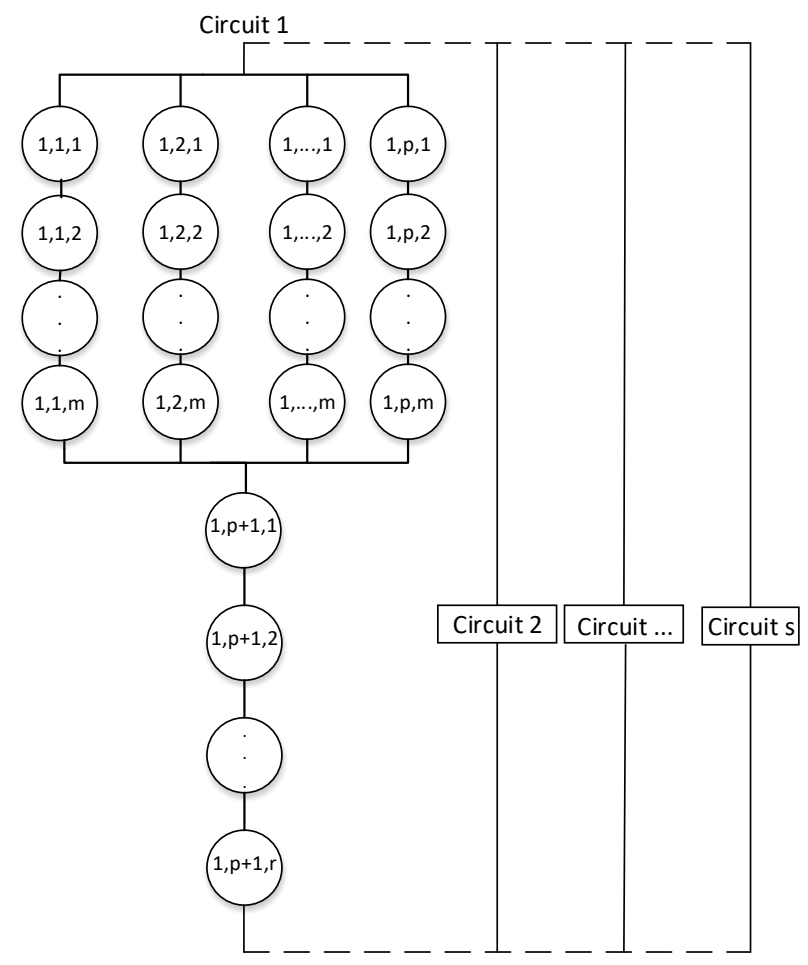

Figure 2: A sketch of a general offshore transmission system used for availability methodology explanation.

Eq. (4) allows the BR to be approximated from CAPEX.

$$
\mathrm{BR}=b \mathrm{CAPEX}+c+\varepsilon_{1}
$$

\subsection{Availability Evaluation}

[32] and [33] evaluate availability by taking the ratio of uptime to total time. We take a similar approach but focus on appropriately considering random variables.

Fig. 2 illustrates a general OTS topology based on the schematics of operational OTSs. Fig. 2 will be used to explain the availability evaluation approach for any OTS. Let the OTS contain $s$ identical (with regards to the major equipment) and independent circuits. For example, circuit 1 is illustrated in Fig. 2. Let each circuit carry $\frac{1}{s}$ of the load through the system. This is a simplification as a real system is likely to include redundancy. Each node, denoted by three numbers $i j k$, represents a component (for example, offshore transformer) in the OTS. The first number, $i$, indicates the circuit a component belongs to, where $i \in I=\{1, \ldots, s\}$. As shown by Fig. 2, each circuit contains parallel branches, where each branch contains components in series. This represents components on the offshore substation. The second number, $j$, denotes which branch the component belongs to where $j \in J=\{1, \ldots, p\}$ and $p$ is the total number of branches. The set of components in each branch is identical across the branches. The third number, $k$, denotes the component in the $j^{\text {th }}$ branch where $k \in K=\{1, \ldots, m\}$ and $m$ is the number of components in each branch. As shown in Fig. 2, these parallel circuits are in series with a string of components that represent the assets connecting the offshore substation to the onshore grid. These are 
indexed by $j=p+1$ and $k \in L=\{1, \ldots, r\}$ where $r$ is the number of components in this string. $C_{i j k \tau}$ denotes the availability of the $i j k^{t h}$ component at any one given point in time, $\tau$. Each component is either working $\left(C_{i j k \tau}=1\right)$ or not working $\left(C_{i j k \tau}=0\right)$. The expected availability of each component is evaluated using its failure and repair rates; this is explained later by Eq. (19). Components are assumed to fail independently.

Since all circuits are identical, the following analysis focuses on circuit 1. At any one given point in time, the availability of circuit $1, A_{1 \tau}$, is:

$$
A_{1 \tau}=\frac{\sum_{j \in J} \prod_{k \in K} C_{1 j k \tau}}{p} \prod_{k \in L} C_{1(p+1) k \tau}
$$

Therefore, by independence and linearity of expectations:

$$
E\left(A_{1 \tau}\right)=\frac{\sum_{j \in J} \prod_{k \in K} E\left(C_{1 j k \tau}\right)}{p} \prod_{k \in L} E\left(C_{1(p+1) k \tau}\right)
$$

The availability of the entire system, $A_{\tau}$, is:

$$
A_{\tau}=\frac{1}{s} \sum_{i=1}^{s} A_{\tau i}
$$

Here, $s$ denotes the number of circuits in the system.

Average yearly availability, $Y_{t}$, is a continuous random variable required to evaluate the revenue stream. $Y_{t}$ is defined as the fraction of time the system is capable of transmitting power [34]:

$$
Y_{t}=\frac{1}{1 \text { year }} \int_{0}^{1 \text { year }} A_{\tau} \mathrm{d} \tau
$$

Average yearly availability, $Y_{t}$, is a different quantity to availability at one point in time, $A_{\tau}$ as shown in Fig. 3.

\subsection{Non-linearity in Contractual Income}

Eq. (3) is non-linear in $Y_{t}$ and therefore, to evaluate the expectation of the contractual income a distribution for $Y_{t}$ is required. On account of the lack of data surrounding availability, a Monte Carlo simulation approach, using hourly discretisation steps to approximate the integral in Eq. (8), has been adopted to determine the distribution for $Y_{t}$. The simulation results, shown in Fig. 3 , indicate very little data (9\% of the 100,000 samples) below $94 \%$ and subsequently, we propose Eq. (9) as a simplified expression to estimate the expected contractual income without capping the risk. Eq. (9) is linear in $Y_{t}$, unlike Eq. (3). This linearity allows the expected yearly system availability to be used, which, under ergodicity, is equal to the expected availability at any given point in time.

$$
\text { Contractual Income } t=\left(0.9+\left(Y_{t}-0.94\right) 2.5\right) \mathrm{BR}
$$




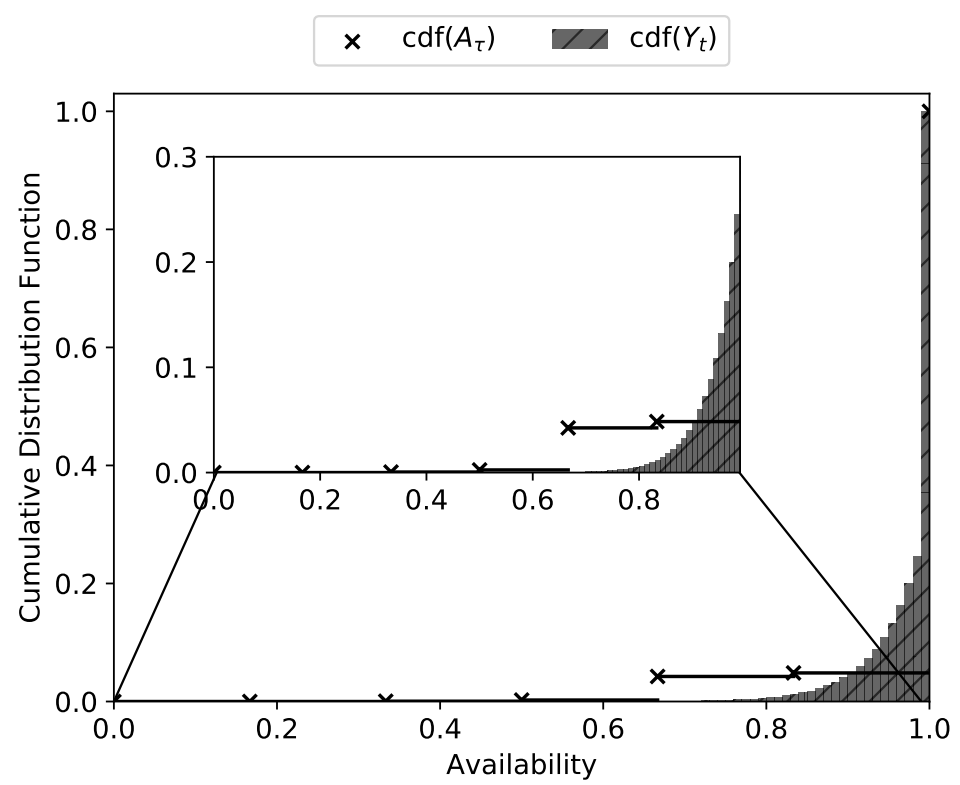

Figure 3: Comparison between the cumulative distribution function of $Y_{t}$ (average yearly availability) and $A_{\tau}$ (availability at any point in time).

Eq. (9) requires the expected yearly system availability:

$$
E\left(Y_{t}\right)=E\left(A_{\tau}\right)=\frac{1}{s} \sum_{i=1}^{s} E\left(A_{i \tau}\right)=\frac{s E\left(A_{1 \tau}\right)}{s}=E\left(A_{1 \tau}\right)
$$

where $A_{\tau i}$ is the availability of circuit $i$ at any one given point in time.

In the scenario considered, the percentage error for using Eq. (9) instead of Eq. (3) is $2.2 \%$. This simplification is only appropriate when the majority of the mass lies above 94\% availability. As the availability falls below $94 \%$, Eq. (9) underestimates the availability with greater error for lower availabilities. However, Eq. (9) consistently gives a conservative estimate to the contractual income, which is suitable when considering a project's NPV as an underestimate will not lead to a risky over-optimistic scenario. This justifies using the simplified Eq. (9) for contractual income.

\section{Loan repayment}

Most economic assessments, not taken from an investor's perspective, consider CAPEX as an upfront cost [9, 11]. The NPV model presented here considers the repayment structure over a repayment period rather than an upfront cost. Under the OFTO regime, the OFTO is required to pay the developer for the assets. The payment amount is called the FTV. FTV is the sum of CAPEX, development, contingency, interest during construction and transaction costs.

The NPV model requires the project's FTV, which is unknown until after the competitive tender process. Accordingly, CAPEX is used to estimate the FTV. CAPEX is chosen for 


\begin{tabular}{c|cc|c} 
& \multicolumn{2}{|c|}{ CAPEX } & \\
\hline Project & $\begin{array}{c}\text { Our Evaluation } \\
(£ M)\end{array}$ & $\begin{array}{c}\text { Ofgem } \\
(£ M)\end{array}$ & $\begin{array}{c}\text { Difference } \\
(\%)\end{array}$ \\
\hline London Array & 357.3 & 343.9 & +3.8 \\
Thanet & 139.8 & 120.3 & +14.0 \\
Gwynt Y Mor & 282.0 & 252.7 & +10.4 \\
West of Duddon Sands & 193.8 & 215.1 & -11.0 \\
Westermost Rough & 129.7 & 122.3 & +6.1 \\
Burbo Bank Extension & 153.6 & 152.6 & -0.6
\end{tabular}

Table 1: Comparison of estimated and actual capital expenditure (CAPEX) values for operational offshore transmission systems (OTSs).

three reasons: it can be estimated with acceptable accuracy (see Section 4.1), it contributes the largest proportion to the FTV, and this proportion can be estimated. Using data from Ofgem cost assessments [30], CAPEX has an average contribution of $77.8 \%$ for projects up to date.

\subsection{Capital Expenditure}

CAPEX refers to the cost to develop, construct, install and commission the OTS [35]. As this value is unknown for future projects, a methodology to evaluate CAPEX is required. This work, similar to [9, 10], proposes a 'bottom-up' approach by summing component costs found in literature [36]. A high-level breakdown of the OTS into offshore substation(s), offshore cable(s), onshore cable(s) and onshore substation(s) is considered. The CAPEX evaluation also includes costs regarding the electrical equipment, platform structures and installation [36.

To validate the modelling strategy and input data used in this 'bottom-up' approach, the CAPEX of six operational OTSs are assessed before estimating the CAPEX for a future project in Section 6.1. The six projects chosen are London Array, Thanet, Gwynt Y Mor, West of Duddon Sands, Westermost Rough and Burbo Bank Extension. Their topologies, found in the Preliminary Information Memorandum for each project [37], combined with data contained in Ofgem's Cost Assessment 30 are used to validate and calibrate this approach. Table 1 shows the results of the CAPEX evaluation.

Our evaluation estimates the CAPEX of London Array, Thanet, Gwynt Y Mor, West of Duddon Sands, Westermost Rough and Burbo Bank Extension to be $£ 357 \mathrm{M}$, £140 M, £282 M, £194 M, £113 M and £137 M respectively. Unfortunately, apart from the occasional exceptions [38, detailed project cost breakdowns are unavailable for those not directly involved.

The NPV model requires CAPEX values in advance of them being published by Ofgem. To use our CAPEX evaluation to predict actual CAPEX values, a linear model is fitted. Due to limited data available, a simple log-log linear model of the form given in Eq. (11) has been chosen. Logarithms are used to reflect a multiplicative error. The intercept and 
slope are given fixed values of one and zero, respectively, since analysis showed them not to differ from these values significantly.

$$
\log \left(\mathrm{CAPEX}_{\text {Ofgem }}\right)=\log \left(\mathrm{CAPEX}_{\text {Own }}\right)+\varepsilon_{2}
$$

$\varepsilon_{2}$, the residual error, is normally distributed with mean zero and standard deviation of $\sigma_{1}$. In $\mathrm{R}$, we obtained $\sigma_{1}=0.09$. On the original (non-log) scale this translates as a $95 \%$ probability of the multiplicative error being between 0.84 and 1.19 .

\subsection{Loan repayment structure}

In the NPV model, the OFTO pays for the transmission assets using a loan as detailed below.

- The loan period is usually between 10 and 15 years [39].

- $n$ denotes the total number of repayment instalments.

- $\ell_{i}$ denotes the interest rate in the $i^{\text {th }}$ instalment period.

- Two sequences of numbers are generated to feed into the NPV model: the repayment amount in each instalment and the outstanding loan amount after each repayment denoted by $P$ and $L$ respectively: $P_{1}, \ldots, P_{n}$ and $L_{0}, L_{1}, \ldots, L_{n}$.

- It is not the purpose of this paper to analyse OFTO debt financing strategies specifically, and therefore the initial loan amount is taken to be the FTV.

- The repayment structure must ensure $L_{0}$, the initial loan amount, is repaid after $n$ instalments and that repayments are constant for a fixed interest rate. Eq. (13) along with Eq. (14) satisfies these two constraints.

- Eq. 13 calculates the repayment amount for the $i^{\text {th }}$ instalment, $P_{i}$. Eq. (14) calculates the outstanding loan after the $i^{\text {th }}$ repayment, $L_{i}$.

$P$ feeds into the NPV model through the node termed loan repayment in year $t$.

$$
\begin{gathered}
\text { Loan Repayment }{ }_{t}=\sum_{i \in \text { All instalments in year t }} P_{i} \\
P_{i}=\frac{L_{i-1} \ell_{i}}{1-\left(1+\ell_{i}\right)^{-(n+1-i)}} \\
L_{i}=L_{i-1}\left(1+\ell_{i}\right)-P_{i}
\end{gathered}
$$

\section{Operational Expenditure}

The NPV model splits OPEX into planned and unplanned OPEX, as shown by Eq. (15). Expenditure due to energy not supplied is not considered under the OFTO regulatory regime.

$$
\mathrm{OPEX}_{t}=\text { Planned } \mathrm{OPEX}_{t}+\text { Unplanned OPEX }_{t}
$$




\subsection{Planned Operational Expenditure}

Offshore transmission owners conduct planned maintenance to ensure good system conditions, prevent future failures and therefore, avoid costly unplanned maintenance. When detailed data is unavailable, yearly planned OPEX is estimated as a percentage, $\alpha$ determined by expert knowledge, of the CAPEX of the OTS [8, 16].

$$
\text { Planned } \mathrm{OPEX}_{t}=\alpha \mathrm{CAPEX}
$$

\subsection{Unplanned Operational Expenditure}

When components fail, offshore transmission owners perform unplanned corrective maintenance to maintain high OTS availability. We only consider the unplanned maintenance of six major pieces of equipment: offshore transformer, offshore switchgear, offshore cable, onshore cable, onshore switchgear and onshore transformer.

Specific asset management strategies are beyond the scope of the paper and, therefore, we assume component replacement upon failure. This approach is a worst-case scenario since, usually, the component will be in a condition where a more economical repair, rather than a complete replacement, is satisfactory. Cable repairs are an exception, since generally only a small section, typically $200 \mathrm{~m}$, of the cable is replaced [16]. Eq. (17) presents the formulation to estimate unplanned OPEX and has been developed from the literature [13, 40, 41].

$$
\left.\underset{\text { UPEX }_{t}}{\text { Unplanned }_{\{x\}}}=\sum_{\text {failure }_{x}}^{\text {Cost per }} \times \underset{\text { failures }_{x, t}}{\text { Number of }_{\text {downtime }_{x}}^{\text {day of }}} \times \begin{array}{c}
\text { Cost per } \\
\text { in days }_{x, t}
\end{array}\right)
$$

Here, $\{x\}$ is the set of components in the OTS.

Eq. (17) contains two random variables: the number of failures and downtime in a year for each component. We find expectations of these variables by modelling each component as a two-state (not working and working) continuous-time Markov chain. $r$ and $f$ represent the component's repair and failure rate respectively. For each component, we obtain the expectation of the random variables required for Eq. (17):

$$
\begin{gathered}
E\left(\text { Number of fails }_{t}\right)=\frac{f r}{f+r} \\
E\left(\text { Downtime }_{t}\right)=\frac{f}{f+r}
\end{gathered}
$$

Eq. (17) contains the variable termed cost per failure. For components located offshore, this is the component replacement cost. However, for components located onshore, it is the replacement and one-off repair cost associated with that component. The variable in Eq. (17) termed cost per day of downtime is zero for onshore components and equal to the daily vessel hire rate for offshore components. 


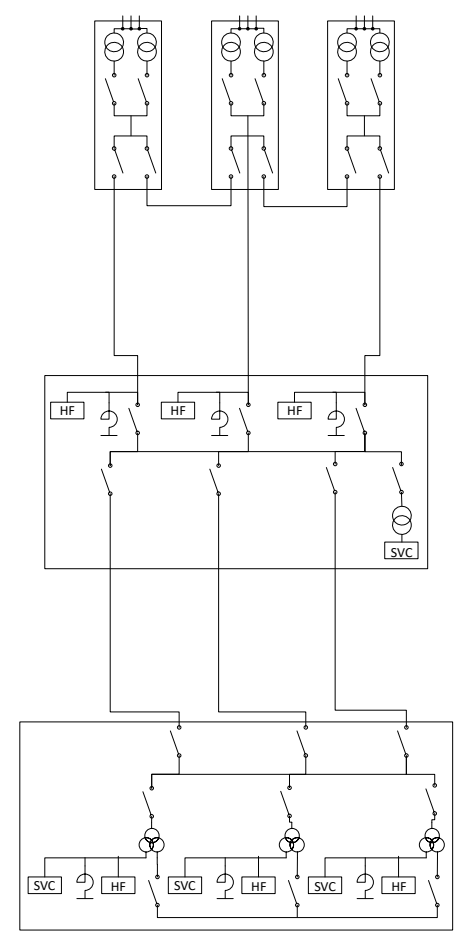

Figure 4: Schematic drawing of the high voltage alternating current (HVAC) offshore transmission system (OTS) used in the case study. 


\begin{tabular}{cc|cc} 
Component & Price $(£ M)$ & Component & Price $(£ M)$ \\
\hline Offshore & & \multicolumn{2}{|c}{ Onshore } \\
\hline Substation & 220.9 & Substation & 85.6 \\
Cable & 640.1 & Cable & 151.3 \\
Reactive compensation unit & 130.9 & &
\end{tabular}

Table 2: Estimated capital expenditure (CAPEX) for the case study.

\begin{tabular}{cccc} 
Component & Availability & Component & Availability \\
\hline \multicolumn{2}{c}{ Onshore } & \multicolumn{2}{c}{ Offshore } \\
\hline Transformer & 0.99819 & Transformer & 0.99879 \\
GIS & 0.99992 & GIS & 0.99995 \\
Cable & 0.99655 & Cable & 0.98381
\end{tabular}

Table 3: Component availability for the case study.

\section{Case Study, Results and Uncertainty Impact Assessment}

\subsection{Case Study}

For the purpose of the analysis in this paper, a case study has been created. The design is based on current trends suggested in [42] and from recent project topologies. The methodology described throughout the paper will be applied to the HVAC OTS shown in Fig. 4. Each project deployed is growing in capacity and distance from the shore. Therefore, the case study is located $140 \mathrm{~km}$ off the coast with a capacity of $1.2 \mathrm{GW}$. A reactive compensation unit and three circuits are considered necessary for this transmission length when approaching with HVAC technologies. Each circuit contains two sets of offshore transformer and offshore switchgear in parallel and then in series with an offshore switchgear, offshore cable $(220 \mathrm{kV}, 140 \mathrm{~km})$, onshore cable $(40 \mathrm{~km})$, onshore switchgear and onshore transformer.

\subsection{Input Data}

The following input data is used to evaluate the NPV of the case study: $3.5 \%$ discount factor [28], 25 year project lifetime, £1228.8 M CAPEX evaluated using the 'bottom-up' approach (a breakdown is shown in Table 2), a 12 year loan period and 4 repayment instalments per year [39]. Inputs for availability, $\alpha$, interest rate and unplanned OPEX are discussed below.

The expected yearly availability of the case study, evaluated using methodology detailed in Section 3.2, is 0.9772649. The expected availability of each component, calculated using component failure and repair rates [33, 43], is shown in Table 3 .

Literature estimates OPEX of cables to be $0.4 \%$ of capital costs [16]. Accordingly, $\alpha$ is assumed to be $0.5 \%$ for the OTS.

Margin rates (interest on top of the base cost of lending) are set by the lender to reflect the expected risk of a project [39]. In 2019, the base cost of lending was $0.75 \%$ [44]. Margin 


\begin{tabular}{|c|c|c|c|c|c|c|c|}
\hline Symbol & 夫 & $\Delta$ & $\stackrel{\times}{\stackrel{\times}{\text { Initial input }}}$ & - & ○ & a & $\begin{array}{c}\text { Worst } \\
\text { Case } \\
\text { Scenario }\end{array}$ \\
\hline$\alpha(\%)$ & - & 0.15 & 0.50 & 0.75 & 1.0 & 1.5 & 1.5 \\
\hline Vessel Hire (£M) & 0.05 & 0.085 & 0.1 & 0.125 & 0.14 & - & 0.14 \\
\hline $\begin{array}{c}\text { Fixed Interest } \\
\text { Rate }(\%)\end{array}$ & - & 1.5 & 3.0 & 6.25 & - & - & 6.25 \\
\hline $\begin{array}{c}\text { Variable Interest } \\
\text { Rate }(\%)\end{array}$ & - & +0.1 & 0 & -0.1 & - & - & - \\
\hline $\begin{array}{l}\text { Failure Rate } \\
\text { (fails/year/km) }\end{array}$ & - & - & 0.000705 & 0.0015873 & 0.00705 & - & 0.00705 \\
\hline $\begin{array}{l}\text { Repair Time } \\
\text { (days) }\end{array}$ & - & - & 60 & 90 & 120 & 150 & 150 \\
\hline$\varepsilon_{2}$ & - & 0.09 & 0 & -0.09 & - & - & -0.09 \\
\hline
\end{tabular}

Table 4: Summary of input parameters and the values considered in the interval analysis. The column denoted by a cross details the initial input scenario. Individually, for each input parameter, the initial input is varied to values shown in this table. The table shows the symbol assigned to each input change that corresponds to Fig. 5. The last column corresponds to the worst-case scenario inputs discussed in the paper.

rates, during the operational phase of an offshore wind project, are between $2.5 \%$ and $4 \%$ [39. Considering this data, a fixed interest rate of $3 \%$ is implemented.

Estimation of unplanned OPEX requires component failure and repair rates given in [33] and [43], component costs given in [36], one off repair costs interpreted from [38] and daily vessel hire rates taken from [40] and [45].

Due to the infancy of the industry, the fate of the OFTO revenue stream beyond the twenty-five year licence is unknown. This case study is designed with a useful economic life of twenty-five years. Therefore, it is assumed that the assets will remain in demand, and a revenue stream is guaranteed for the project's entire lifetime [26].

\subsection{Results}

For the described input data, the model estimates the expected NPV for the case study to be $£ 195 \mathrm{M}$. Breaking this down into the cash flow contributions: the expected yearly contractual income is $£ 113 \mathrm{M}$ during the project's lifetime, and the expected loan repayments are $£ 157 \mathrm{M}$ for the first twelve years of the project. The remaining contributions are the expected planned and unplanned OPEX, evaluated to be $£ 6 \mathrm{M}$ and $£ 2 \mathrm{M}$, respectively, for each year of operation. For the chosen input data, the project is unprofitable in the first twelve years due to the large loan repayments; this could be critical to some offshore transmission owners. Overall the project is profitable; however, many assumptions are required for the analysis, and some input values have severe uncertainty associated with them. 


\subsection{Uncertainty and Sensitivity Analysis}

The quantification of the case study requires the input parameters discussed in Section 6.2. It may not always be possible to know these input parameters with certainty, and thus the model will contain uncertainty. The following section aims to, through sensitivity analysis, identify the variables that, due to their uncertainty, could have a significant impact on the project's expected NPV. As it is difficult to put realistic distributions on these parameters, we will consider reasonable ranges for these parameters instead, and see how values in these ranges affect the NPV. By doing so, we assess the economic impact of real-world variations on key and uncertain aspects of the project.

The sensitivity analysis considers the following parameters: $\alpha$, vessel hire rate for cable repairs, interest rate, offshore cable failure rate, offshore cable repair time and $\varepsilon_{2}$. The choice of values for each parameter is discussed below and presented in Table 4.

$\alpha$ is determined by expert knowledge and therefore contains uncertainty. As suggested by literature [8, 10, 16], $\alpha$ values between $0.15 \%$ and $1.5 \%$ are considered.

Literature quotes vessel hire rates between $£ 0.05 \mathrm{M}$ and $£ 0.14 \mathrm{M}$ [40, 45].

Due to the uncertain nature of interest rates, three reasonable 44] fixed interest rates of $1.5 \%, 3 \%$ and $6.25 \%$, as well as variable interest rates, are considered. The variable interest rate starts in year one at 3\% and then follows one the following two extreme scenarios for subsequent years: the rate increases each year by $0.1 \%$ or the rate decreases each year by $0.1 \%$.

Industry experience points out that the failure rate used in this paper, 0.000705 fails $/$ year $/ \mathrm{km}$ [43], could be too small [41]. Therefore, the sensitivity analysis considers two failure rates: ten times the value quoted in the literature to observe the impact of a larger failure rate and a failure rate of 0.0015873 fails/year $/ \mathrm{km}$ based on current experience [41].

Repair times are quoted in the literature between 2 and 5 months [43].

Since the CAPEX linear model is only based on six data points, the model parameters contain uncertainty. Based on the residuals of individual data points, the impact of varying $\varepsilon_{2}$ in Eq. (11) between -20 and 30 is assessed.

The sensitivity analysis varies the variables, singly, as discussed above. The resulting expected NPV for each scenario is plotted in Fig. 5. Table 4 shows the values of each variable analysed and the corresponding symbol on Fig. 5. With the input variables considered in Table 4, Fig. 5 shows that daily vessel hire rates and variable interest rates have a small impact on the project's expected NPV. Cable failure rate, fixed interest rate and planned OPEX appear to have a critical impact, with the sensitivity analysis indicating a negative expected NPV for some input values. The sensitivity analysis also shows that increasing the repair time of an offshore cable, a variable influenced by the inherent uncertainties associated with offshore wind, also significantly impacts the expected NPV.

As shown in Fig. 5, increasing cable failure rate by a factor of ten results in the expected NPV falling to $-£ 609 \mathrm{M}$. This decrease is a combination of increased unplanned OPEX and the effect of Eq. (9). As stated in Section 3.2. Eq. (9) underestimates the expected contractual income for availabilities less than 94\%. This underestimation is applicable here since a failure rate of 0.00705 fails $/$ year $/ \mathrm{km}$ results in $85 \%$ availability. Under the OFTO regulatory regime, the contractual income is capped at $90 \%$ of the $\mathrm{BR}$, and thus the expected 


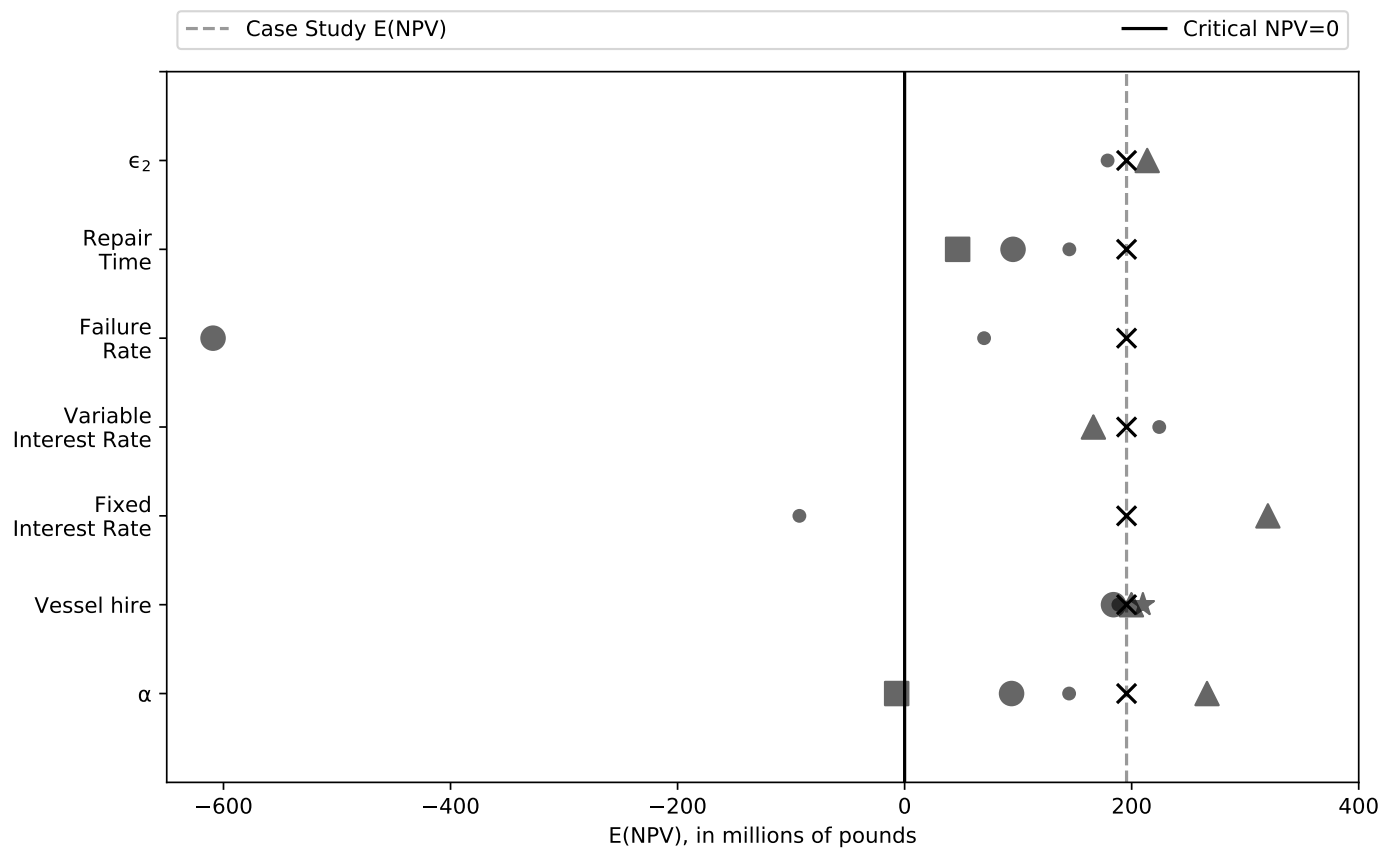

Figure 5: Interval analysis of uncertain input parameters. The symbols and their corresponding numerical inputs are presented in Table 4

NPV would be $-£ 208 \mathrm{M}$. This negative NPV still suggests a very unfavourable project and highlights the large impact of failure rate on expected NPV. This example also highlights the safety provided to the OFTO through the regulatory regime.

Fig. 5 indicates that both an increased failure rate and longer repair time result in a lower expected NPV. These two variables influence system availability and therefore, a lower availability results in a smaller expected NPV. The OFTO regulatory regime provides some protection; however, a $94 \%$ availability results in a significantly lower expected profit compared to $100 \%$ availability. Therefore, further work into increasing the availability of an OTS should be investigated, especially when aiming to maximise profit.

A worst-case scenario, with regards to input data, resulted in an expected NPV of -£1889 M, a very unfavourable project. The last line of Table 4 shows the input data for the worstcase scenario. This scenario has $71 \%$ availability, and consequently, Eq. (9) underestimates the contractual income as previously described. Under the OFTO regulatory regime, the expected NPV is $-£ 885 \mathrm{M}$, still an unfavourable project.

This investigation provides a deeper understanding of the uncertainties associated with offshore transmission and highlights the importance of assessing their impact on economic performance. Our findings indicate that some of the uncertain input parameters have a significant impact on the economic evaluation. As project planning and investment decisions may be based on these economic assessments, the conclusions of this study have significant implications for decision makers in offshore wind transmission. On account of the insights 
gained, care should be taken when economically evaluating projects under severe uncertainty. In particular, the results indicate that the offshore cable failure rate has a notable impact on NPV, and therefore the input value for this parameter should be carefully considered. Furthermore, techniques to handle these uncertainties should be explored and implemented.

\subsection{Comparison to real life projects}

Due to a lack of publicly available data, comparison of a full economic evaluation to real-life projects is beyond the scope of this paper. However, access to some data allows a comparison between individual parts of the economic model. In Section 4.1, we compare our CAPEX evaluation to real project CAPEX values. In this subsection, we compare two more parts of the proposed model with real-life data: the operational expenditure of offshore cables and the availability of the offshore transmission systems.

The operational expenditure of offshore cables for some operational projects is reported to be on average $£ 12.5 \mathrm{M}$ per repair in [41]. For the case study considered, an offshore cable failure lasting 60 days has an expected repair cost of $£ 6.1 \mathrm{M}$ and an offshore cable failure lasting 150 days has an expected repair cost of $£ 15.1 \mathrm{M}$. These figures are in good agreement with the average repair cost of $£ 12.5 \mathrm{M}$.

In the UK, the availability of offshore transmission systems is reported in [34]. Over the last eight years that the reports have been published, yearly availability values have ranged between $82.47 \%$ and $100 \%$, with an average yearly availability of $98.7 \%$. It is important to note that these values are for a range of different projects that each have their design specification, located at varying distances from shore, and importantly all have a smaller capacity than the offshore wind project considered here. For the case study considered, using the initial input data, results in a yearly availability of $97.7 \%$. During the sensitivity analysis shown in Fig. 5, the availability of the offshore transmission system ranged between $85.5 \%$ and $97.7 \%$. These results suggest that the availability values obtained in this work are in good agreement with the data given in [34].

\section{Conclusion}

This paper presents model formulation and analysis from the offshore transmission owner's perspective in the UK. A NPV model, formulated using the literature available, considers revenue stream, loan repayments and OPEX, among other details that enables it to be applied in many OTS planning and asset management scenarios. The novelty of this economic assessment is based on incorporating an offshore transmission regulatory regime and including the FTV repayment structure. The methodology is implemented on a 1.2 GW project which required the collection and curation of useful data regarding CAPEX, availability and OPEX from a variety of sources.

During the quantification process, many areas were highlighted to contain severe uncertainty with regards to the input data. This study investigates six input parameters that are uncertain to a degree where it is difficult to assign them a distribution. Interval analysis is conducted to quantify the economic impact of these uncertainties on project performance. 
This work shows that loan interest rate, cable failure rates and planned OPEX are unknowns in offshore power transmission that are critical to the offshore transmission owner's profit.

The results of this study indicate that cable failures have a significant impact on the economic evaluation of an offshore wind transmission project, and strengthens the idea that further research into offshore cable reliability could be beneficial to the industry. Additionally, further work could explore advanced statistical techniques, that handle severe uncertainties, and incorporate these techniques into economic evaluations. This advancement could have useful implications for decision makers in offshore transmission. Finally, as the industry matures, and there is more data, it will be interesting to revisit this study and re-evaluate the impact of uncertainty on economic evaluations based on the data available at that time.

\section{Acknowledgements}

Henna Bains is funded by an Offshore Renewable Energy (ORE) Catapult Doctoral Studentship.

\section{References}

[1] The Fifth Carbon Budget: The next step towards a low-carbon economy, Committee on Climate Change (2015).

Available at: https://www.theccc.org.uk/wp-content/uploads/2015/11/Committee-on-Climate -Change-Fifth-Carbon-Budget-Report.pdf

[2] Global wind report 2018, Global Wind Energy Council (2019). Available at: https://gwec.net/global-wind-report-2018/

[3] Connecting offshore wind farms. A Comparison of Offshore Electricity Grid Development Models in Northwest Europe, Navigant Netherlands B.V. (2019).

Available at: https://guidehouse.com/-/media/www/site/downloads/energy/2019/2019-navi gant-comparison-offshore-grid-development.pdf?la=en

[4] H. Bains, A. Madariaga, B. Kazemtabrizi, M. C. M. Troffaes, The impact of offshore transmission regulatory regimes on technology choices, in: CIGRE Symposium Aalborg, 2019, pp. 637-650.

[5] C. Delhaute, F. Gargani, S. Boeve, S. Bonafede, S. Rapoport, Study on regulatory matters concerning the development of the North and Irish Sea offshore energy potential - Final report, PwC, Tractebel Engineering and Ecofys for the European Commission (2016).

Available at: https://op.europa.eu/en/publication-detail/-/publication/cf1b6dd1-05f011e6-b713-01aa75ed71a1

[6] C. Williams, Offshore Transmission. Market Update., PricewaterhouseCoopers LLP (2018). Available at: https://www.ofgem.gov.uk/system/files/docs/2018/10/pwc_ofto_tr6_market_ update.pdf

[7] Generic Offshore Transmission Owner (OFTO) Licence for TR6, Ofgem (2018). Available at: https://www.ofgem.gov.uk/publications-and-updates/offshore-transmission-g eneric-ofto-licence-and-guidance-tr6

[8] P. Bresesti, W. L. Kling, R. L. Hendriks, R. Vailati, HVDC connection of offshore wind farms to the transmission system, IEEE Transactions on energy conversion 22 (1) (2007) 37-43.

[9] J. Serrano González and M. Burgos Payán and J. Riquelme Santos, Optimum design of transmissions systems for offshore wind farms including decision making under risk, Renewable Energy 59 (2013) 115 $-127$. 
[10] B. Van Eeckhout, D. Van Hertem, M. Reza, K. Srivastava, R. Belmans, Economic comparison of VSC HVDC and HVAC as transmission system for a $300 \mathrm{MW}$ offshore wind farm, European Transactions on Electrical Power 20 (5) (2010) 661-671.

[11] S. Afanasyeva, J. Saari, M. Kalkofen, J. Partanen, O. Pyrhönen, Technical, economic and uncertainty modelling of a wind farm project, Energy Conversion and Management 107 (2016) 22 - 33, special Issue on Efficiency, Cost, Optimisation, Simulation and Environmental Impact of Energy Systems (ECOS)2014.

[12] A. Ioannou, A. Angus, F. Brennan, Stochastic prediction of offshore wind farm LCOE through an integrated cost model, Energy Procedia 107 (2017) 383 - 389.

[13] M. Shafiee, F. Brennan, I. A. Espinosa, A parametric whole life cost model for offshore wind farms, The International Journal of Life Cycle Assessment 21 (7) (2016) 961-975.

[14] O. Salo, S. Syri, What economic support is needed for Arctic offshore wind power?, Renewable and Sustainable Energy Reviews 31 (2014) 343 - 352.

[15] M. Dicorato, G. Forte, M. Pisani, M. Trovato, Guidelines for assessment of investment cost for offshore wind generation, Renewable Energy 36 (8) (2011) 2043 - 2051.

[16] D. Westermann, A. Küster, D. Van Hertem, D. Soerangr, G. Real, M. Meisingset, M. Takasaki, T. Rauhala, B. Klöckl, M. Kurrat, et al., Voltage source converter (VSC) HVDC for power transmissioneconomic aspects and comparison with other AC and DC technologies, Electra 261 (2012) 59-65.

[17] A. Sajadi, L. Strezoski, K. Clark, M. Prica, K. Loparo, Transmission system protection screening for integration of offshore wind power plants, Renewable Energy 125 (2018) 225-233.

[18] J. S. González, A. G. Rodríguez, J. C. Mora, M. B. Payán, J. R. Santos, Overall design optimization of wind farms, Renewable Energy 36 (7) (2011) 1973-1982.

[19] S. Afanasyeva, J. Saari, S. Kukkonen, J. Partanen, O. Pyrhönen, Optimization of wind farm design taking into account uncertainty in input parameters, in: Proceedings of the European Wind Energy Conference and Exhibition, 2013, pp. 1-10.

[20] J. Warnock, D. McMillan, J. Pilgrim, S. Shenton, Failure rates of offshore wind transmission systems, Energies 12 (14) (2019) 2682.

[21] The R project for statistical computing, http://www.r-project.org/.

[22] S. V. D. Walt, S. C. Colbert, G. Varoquaux, The NumPy array: a structure for efficient numerical computation, Computing in Science \& Engineering 13 (2) (2011) 22-30.

[23] J. D. Hunter, Matplotlib: A 2D graphics environment, Computing In Science \& Engineering 9 (3) (2007) 90-95

[24] P. O'Donovan, Offshore Transmission: Updated Guidance for Cost Assessment, Ofgem (2017). Available at: https://www.ofgem.gov.uk/system/files/docs/2017/07/170629_update_cost_ assessment_guidance _- 0. pdf

[25] I. Groenewald, Offshore Transmission Revenue and Incentive Reporting: Regulatory Instructions and Guidance, Ofgem (2016).

Available at: https://www.ofgem.gov.uk/ofgem-publications/99702

[26] Offshore Transmission: An Investor Perspective, KPMG (2012). Available at: https://www.ofgem.gov.uk/sites/default/files/docs/2012/12/ofto-an_investo r_perspective_0.pdf

[27] A. Madariaga, Facilitating cost reduction through the review of offshore grid standards: single transformer substation evaluation, ORE Catapult (2016).

Available at: https://ore.catapult.org.uk/app/uploads/2017/12/Facilitating-cost-reducti on-through-the-review-of-offshore-grid-standard.-Single-transformer-substation-e valuation.pdf

[28] The Green Book. Appraisal and Evaluation in Central Government, HM Treasury (2011). Available at: https://www.gov.uk/government/publications/the-green-book-appraisal-andevaluation-in-central-governent

[29] H. Evans, Guidance on the Offshore Transmission Owner Licence for Transitional Tender Round 2, Ofgem (2013). 
Available at: https://www.ofgem.gov.uk/sites/default/files/docs/2013/09/generic_offsho re_transmission_owner_licence_guidance_v1_5_1.pdf

[30] Cost Assessments for all Operating Offshore Transmission Systems, Ofgem (2018). Available at: https://www.ofgem.gov.uk/electricity/transmission-networks/offshore-tran smission/publications-library-offshore-transmission

[31] N. R. Draper, H. Smith, Applied regression analysis, Vol. 326, John Wiley \& Sons, 1998.

[32] R. Billinton, R. N. Allan, Reliability evaluation of engineering systems, Springer US, Boston, MA, 1992.

[33] A. Beddard, M. Barnes, Availability analysis of vsc-hvdc schemes for offshore windfarms, in: 6th IET International Conference on Power Electronics, Machines and Drives (PEMD 2012), 2012, pp. 1-6.

[34] National Electricity Transmission System Performance Reports 2011 - 2019. Report to the Gas and Electricity Markets Authority, National Grid (2012-2019).

Available at: https://www.nationalgrid.com/uk/electricity/market-operations-and-data/ transmission-performance-reports

[35] I. Groenewald, Offshore Transmission Owner Revenue Report, Ofgem (2016).

Available at: https://www.ofgem.gov.uk/publications-and-updates/offshore-transmission-o wner-revenue-report-0

[36] Electricity Ten Year Statement 2013, 2014, 2015: Appendix E - Technology., National Grid (2013 2015).

Available at: https://www.nationalgrideso.com/publications/electricity-ten-year-stateme nt-etys

[37] Preliminary Information Memorandum for West of Duddon Sands Offshore, London Array, Thanet, Gwynt Y Mor, Westermost Rough and Burbo Bank Extension Transmission Assets, Ofgem (2009 2016).

Available at: https://www.ofgem.gov.uk/publications-library

[38] West of Duddon Sands Transmission Assets, Ex Ante Technical Investigation, Fichtner Consulting Engineers Limited (2015).

Available at: https://www.ofgem.gov.uk/sites/default/files/docs/2015/08/6._wods_ca_appe ndix_6_fichtner_ex-ante_technical_review.pdf

[39] Where's the money coming from? Financing offshore wind farms, European Wind Energy Association (2013).

Available at: http://www.ewea.org/fileadmin/files/library/publications/reports/Financi ng_Offshore_Wind_Farms.pdf

[40] R. Martin, I. Lazakis, S. Barbouchi, L. Johanning, Sensitivity analysis of offshore wind farm operation and maintenance cost and availability, Renewable Energy 85 (2016) $1226-1236$.

[41] Export Cable Reliability, Description of Concerns, Offshore Wind Programme Board (2017). Available at: https://ore.catapult.org.uk/app/uploads/2018/02/Export-Cable-ReliabilityStep-1-v7-UPDATE-Jul-17.pdf

[42] Offshore Wind in Europe. Key trends and statistics 2017., Wind Europe (2018).

Available at: https://windeurope.org/wp-content/uploads/files/about-wind/statistics/Wi ndEurope-Annual-Offshore-Statistics-2017.pdf

[43] R. Rosevear, M. Choquette, M. Fairhurst, H. Jorgensen, J. Larsen, B. Mampeay, A. Rakowska, S. Tricoli, V. Waschk, Update of service experience of HV underground and submarine cable systems, CIGRE TB 379 (2009) 1-84.

[44] Bank of england: Interest rates and bank rate Available at: https://www.bankofengland.co.uk/monetary-policy/the-interest-rate-bankrate

[45] A. Ioannou, L. Wang, F. Brennan, Design implications towards inspection reduction of large scale structures, Procedia CIRP 60 (2017) $434-439$. 